\title{
Computer science and technology : historiography III (2)
}

Camille Akmut

March 3, 2022

\begin{abstract}
VG, PC and hacker magazines; applied and theoretical computer graphics; cyberpunk.
\end{abstract}




\section{PRIMARY SOURCES : VIDEO GAME MAGAZINES}

From official-est accounts to underground, and in-between.

— Nintendo Power (1988-..), Electronic Gaming Monthly (89-.)

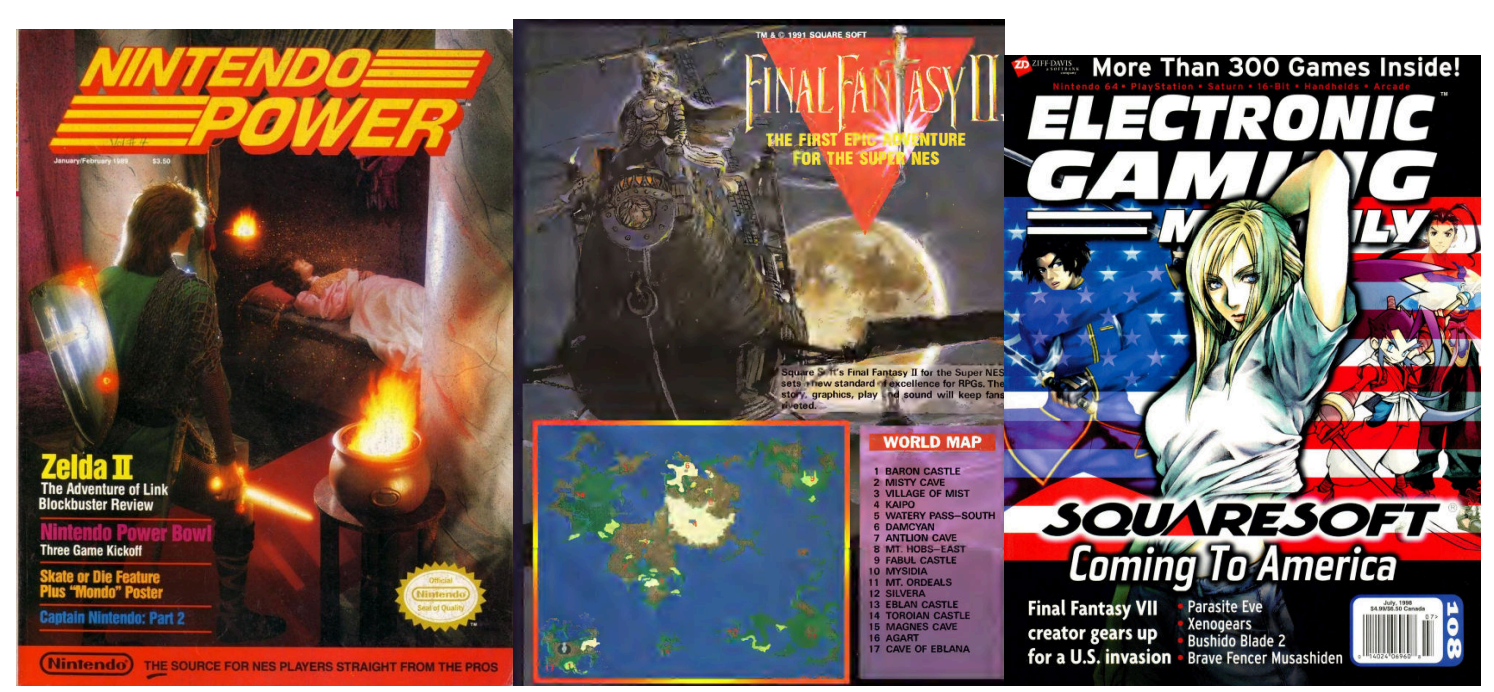

Illustration - vol. 4 and 30 of Nintendo Power

the official magazine by Nintendo America : issues contain guides to several games with one featured (above Final Fantasy II) e.g. detailed maps, lists of items, puzzles, and also comics, various rankings, player profiles, ads (e.g. 'super scope' peripheral...) Consoles covered : Game Boy, NES, Super NES... as long as Nintendo.

Magazines such as this one or Electronic Gaming Monthly founded around the same time, represent a certain era in gaming that - at least into the 2000's - was mostly untouched by politics, leading to a very nostalgic but completely uncritical vision of mainstream video games reporting i.e. journalism conceived as advertisement.

Example content

\begin{tabular}{|l|l|c|l|}
\hline Nintendo Power & jan.-feb. 1989 & 4 & Zelda II \\
& oct. 1990 & 17 & Final Fantasy \\
& nov. 1991 & 30 & Final Fantasy II ("the first epic adventure for the Super NES") \\
& may 1997 & 94 & Final Fantasy VII \\
& may 1998 & 106 & RPG Revolution ("Parasite Eve") \\
& july 1998 & 108 & Squaresoft Coming To America \\
\hline
\end{tabular}

- Video Games (1982-..), Edge (1993-..)

At the other end of "official" are, one magazine that precedes the home gaming boom (e.g. the Western introduction of the Nintendo Entertainment System) and another not from the United States : 
In Video Games' second issue John Holmstrom - also contributor to acclaimed Heavy Metal $^{1}$ - offers a comic about a young man playing video games ("four men left!") while his date is being chatted up by someone else... Another article focuses on the development of video games ("the art of"...).

In Edge, a U.K. magazine, events such as the Japanese Amusement Operators' Union show (issue 8), and the Tokyo Toy Show become the occasion for ethnographystyle trip reports, for instance (including lots of photos).
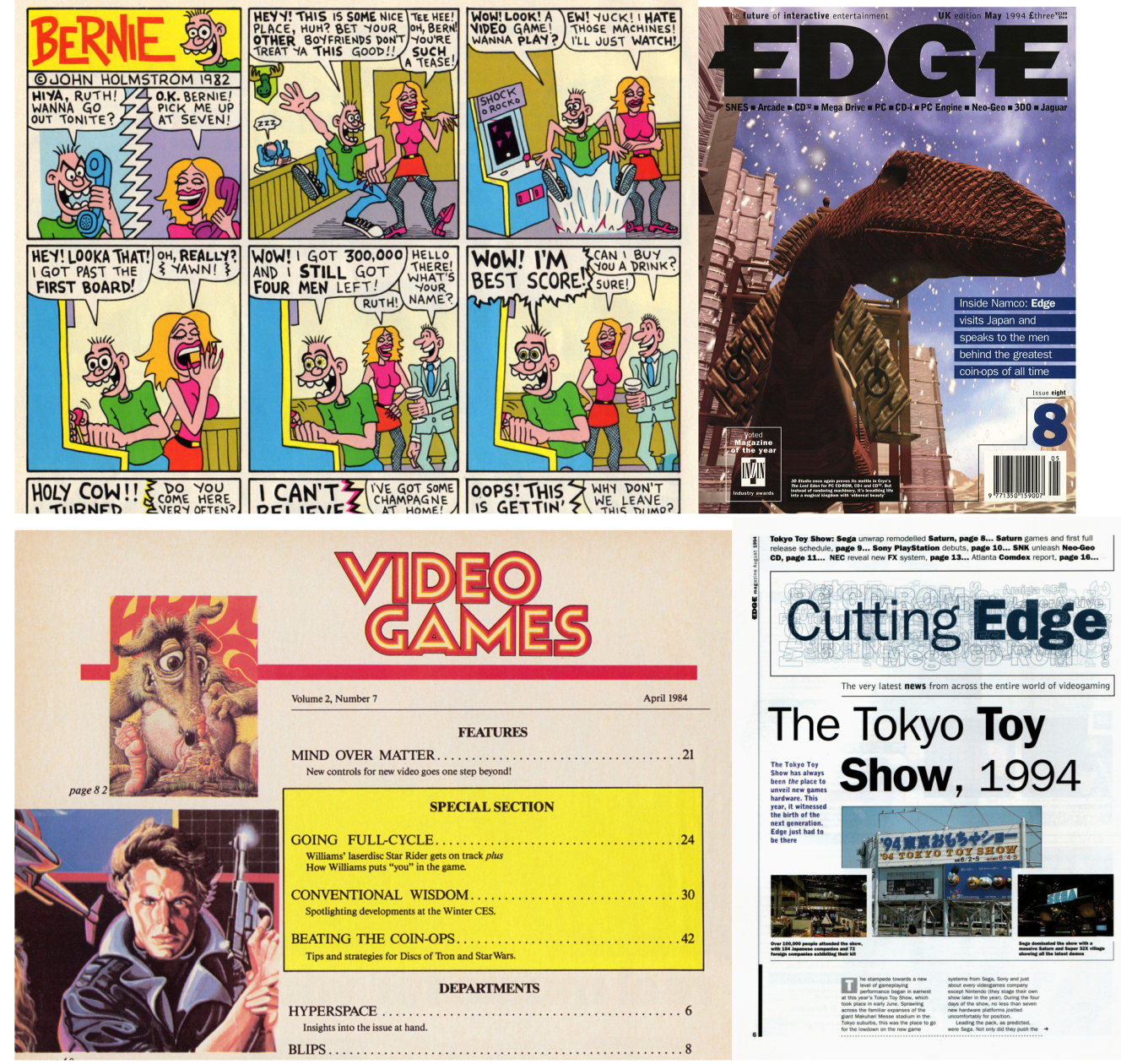

Il. : issues 2 and 19 of Video Games, 8 and 11 of Edge

\section{ARCHIVES}

https://www.retromags.com/ (VG magazines systematically preserved by digital archivists)

\footnotetext{
${ }^{1}$ Publisher among others of Moebius comics...
} 


\title{
COMPUTER GRAPHICS / VIDEO GAMES (IN LISP)
}

\author{
- Way of the Warrior (1994); Crash Bandicoot (1996-...)
}

Interviewed $^{1}$, Andy Gavin retraced the context of computer graphics at the time, in part. the advantages of -developing for- consoles over PC's like this :

"there were two main custom chips in the PlayStation 1, a graphics unit and a sort of custom MIPS CPU. [The GPU] could draw about 120,000 polygons a second of triangles which was phenomenal.

If you were using a PC at the time, they had no 3D graphics hardware. They had like VGA boards. You'd be lucky to get a couple hundred polygons because you had to do them all in the software.

But here was the PlayStation which was gonna be like [299\$]. And it was like a complete machine (...) Console machines like compared to PCs at the time, a world of difference.

We're talking Windows 3.1 and DOS. To run a game, you usually had to have a boot disk with like custom AutoExec bash and config.sys and you had to open up your machine. This was not a very game friendly world on PCs.

But PlayStation or Genesis or a Super Nintendo, you just (...) pushed on, boom, it booted. I liked the Sony best. It was neat and clean and powerful and intended for 3D."

Essentially, the goal was to develop a 3D version of a platform game like Donkey Kong Country [1994, SNES] which is cited as an influence, as well as classic cartoons and the animation renaissance : Looney Tunes, DuckTales, Simpsons...

Gavin exclaims "no one had ever made a 3D platform action game."

The resulting game, Crash Bandicoot [1996], was very distinctive for its bright, rich colorful style. Compare with Lara Croft's Tomb Raider, a game of the same year, blocky, gray-ish world.
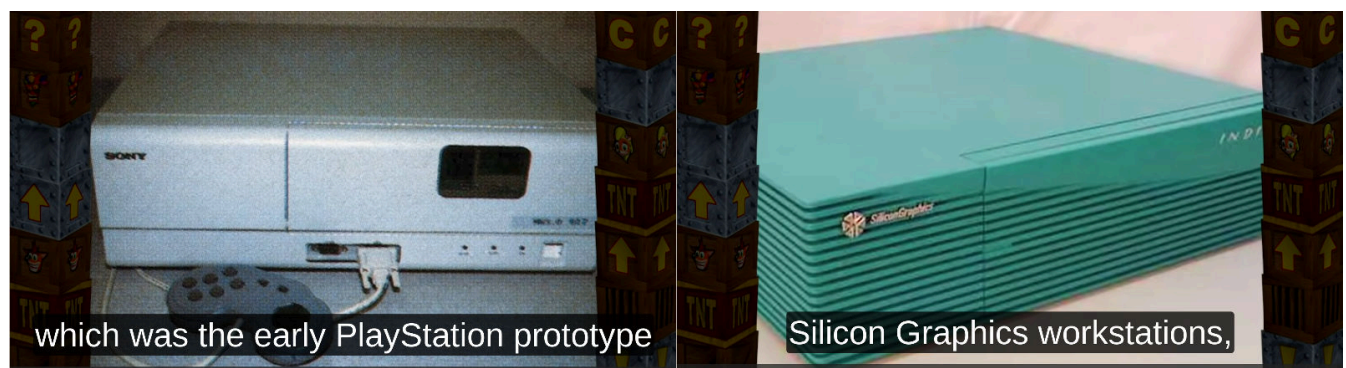

For developing the game, average computers would not do (as already explained) thus they bought for the company, "about five people at this stage, Silicon Graphics workstations. Mostly Indigo2 Extremes. These are like 75 to $\$ 100,000$ workstations. They had $3 D$ graphics. This was what people had done in recent, very recent memory at the time, Terminator 2 or The Abyss or even Jurassic Park."

\footnotetext{
1 "Crash Bandicoot Co-Creator Andy Gavin", 2020, ArsTechnica. pSHj5UKSylk A shorter version also exists (izxXGuVL21o). Illustrations from figures 1 and 2 come from these.
} 
The "early PlayStation prototype" / development model came with " a bunch of manuals which are incredibly badly translated from the Japanese and are mysterious and you'd have amusing debates between the programmers what they actually meant by the funny choice of English words."

The process of figuring out how the Playstation 1 worked is described as follows :

"The way to really figure out what to do is to test things empirically. You do that by taking the individual pieces and you write test code to do certain things on the machine and put it through its paces,

so like taking a car out on a track and seeing how fast it can actually corner."

A hack, or clever modification by the studio Naughty Dog was to use the CD storage as additional space to the -faster but smaller- memory of the Playstation. (Hence also the loading segments characteristic of this work.)

They made use of the console's computer graphics capabilities like so : "30 frames a second and we got about 1,500 polygons on the screen. 600 of them went to Crash. That's how important he was to us."

Chapter 13 of the extended interview concerns G.O.O.L., the "game oriented object Lisp" created as a domain specific language (DSL) for this game [the idea being : before creating a game, to create a language suited for games, or a project specifically].

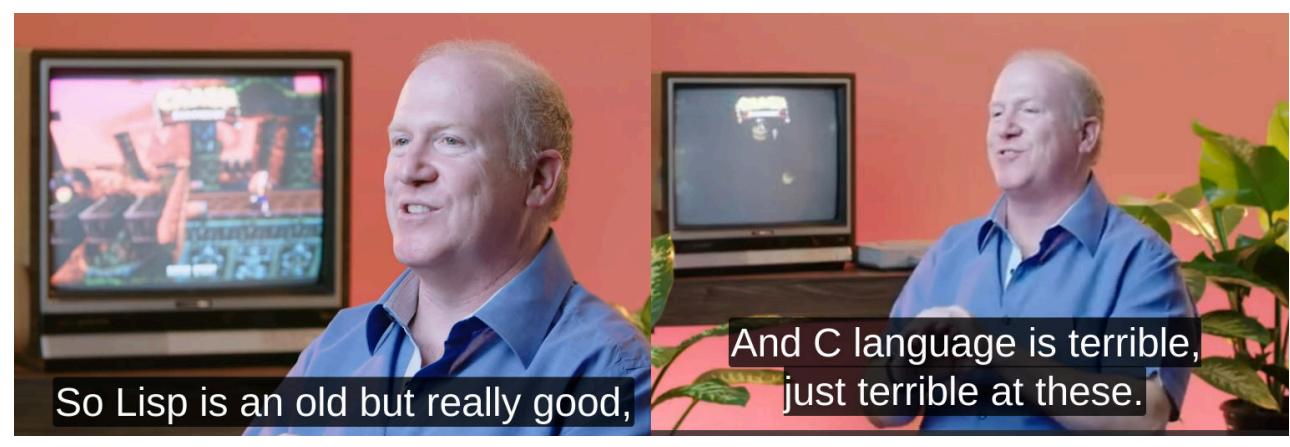

Andy Gavin on the benefits of a Lisp video game DSL

“At MIT (...) my advisor was a guy named Rod Brooks, who's a very famous roboticist.

He's one of the founders of company that makes the Roomba. Rod, and I through extension, were big fans of like the Lisp programming language and this sort of philosophical idea with programming of make your language suit the problem. (...)

So Rod was very into this idea of domain-specific programming.

And he had written a number of his own languages for like controlling robots.

So Lisp is an old but really good, sophisticated AI language, that was designed for AI." 
"in earlier video game programs, like my earlier games, like before Way of the Warrior, was this problem, how to write video game objects,

things like, in Crash, it's like Crash himself, the skunks, the displays, like fruits, boxes, bouncy platforms.

These things are all written with state machines, and regular programming languages, historically, made state machines incredibly, (...) awkward.

And $\mathrm{C}$ language is terrible, just terrible at these. So it was just really difficult and annoying to write something like a platform

(...)

So I wrote a simple version of this, like my first major iteration of this, in Way of the Warrior,

and all of the characters in [it] and their different moves and sequences, which are also state machine, typical video game things, are all written in this language."

\section{- Jak and Daxter (2001-...)}

Compared with Crash Bandicoot, their design goal was this time to create a continuous world (with no loading, interruption times that would signify ending or beginning levels). They cite the release of Mario 64 as big influence. (The latter was developed for the Nintendo 64, this one for the PS2. $)^{2}$

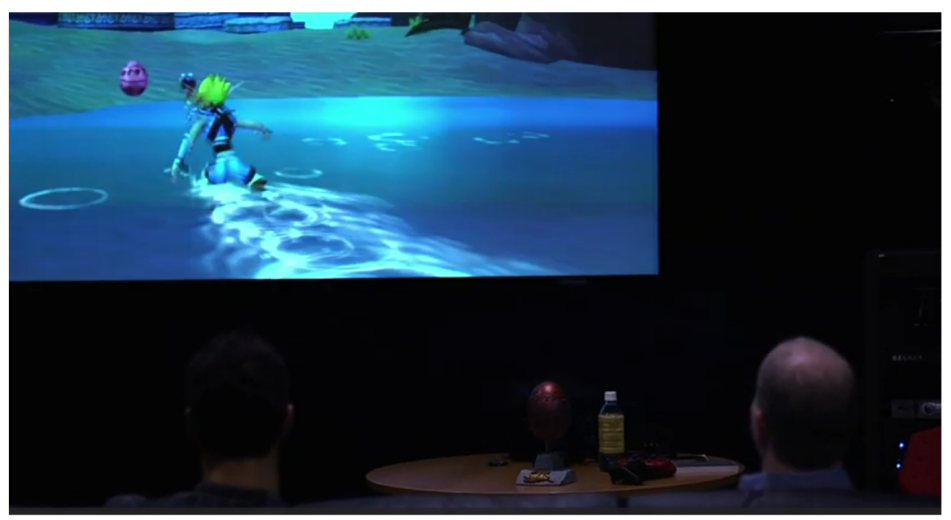

The first illustration shows the Naughty Dog studio founders Jason Rubin and Andy Gavin, (who were best friends and roommates), playing the game and providing commentary for e.g. changing character animations in different environments, for instance water here.

In the second illustration : Lisp-like code (commented out) with what looks like $\mathrm{C}++$-like code above, presumably belonging to the original and the port respectively.

The studio responsible compares the process of porting older games to new consoles to "restoring old film", and bringing "classics to the modern era", where the main concern is fidelity (" $100 \%$ we are faithful to the original"). "It's like remixing the

\footnotetext{
${ }^{2}$ For this section, we rely mostly on a documentary, Jak and Daxter. Remastering the Memory. LHvUjmlWRAI (published under less accurate title "The Making of Jak \& Daxter")
} 


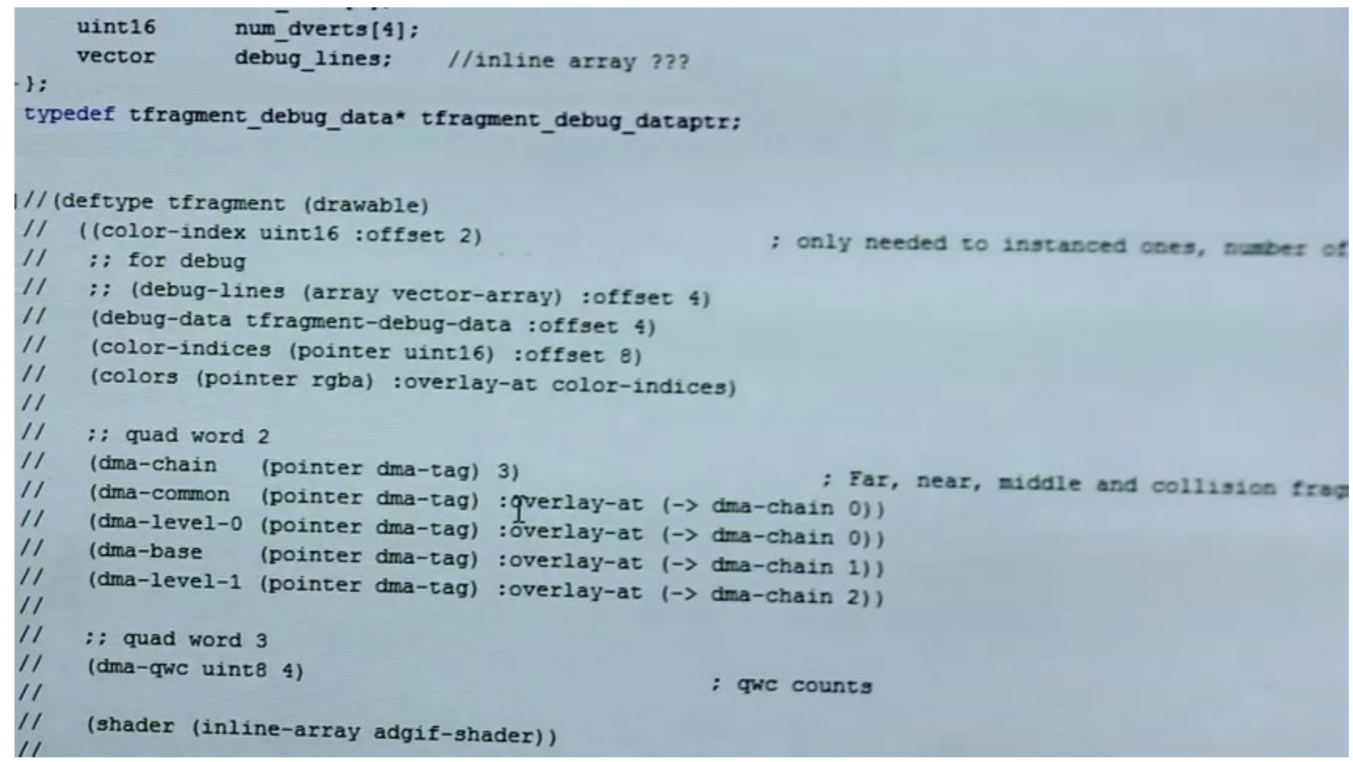

Figure 1: Source code from porting Jak and Daxter

Beatles album, or something" another staff comments. Yet another proposes that "To some extent you remaster your own memories"...

See also "Postmortem: Naughty Dog's Jak and Daxter: the Precursor Legacy" (Gamasutra, 10/07/2002)) for more details or further code examples.

\section{- Donkey Kong Country (1994-...)}

It was created on the Challenge, "this really advanced super computer, basically, picture 20 super computers in a box (...) The same computers are used in Terminator 2 , Jurassic Park, in movies like True Lies"

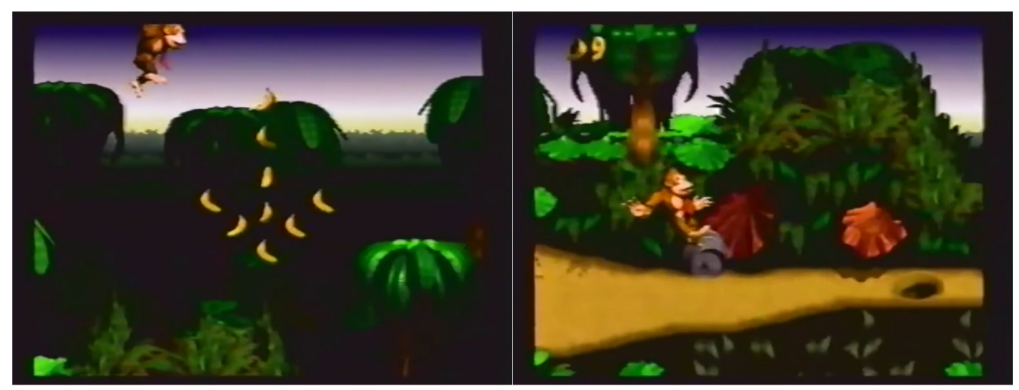

From the documentary The Making of Donkey Kong Country $15 \mathrm{~min}$

(a hack in the first level, demonstrated by QA staff)

Computer scientist Jim Clark is the founder of Silicon Graphics : See the Catmull-Clark subdivision. Edwin Catmull founded Pixar... 


\section{MONOGRAPHS}

- Hughes et al.. 2013. Computer Graphics: Principles and Practice. Addison-Wesley.

The Catmull-Clark subdivision is treated in chapter 23, following the one on curves, with the explanation that: "Spline surfaces and subdivision surfaces are natural generalizations of spline and subdivision curves."

- McKusick, Marshall. 2014[2004]. The Design and Implementation of the FreeBSD Operating System, Addison-Wesley

Reference work by one of the BSD creators. "History and Goals" (circa 20 pages).

- Lucas, Michael. 2013[2003]. Absolute OpenBSD: UNIX for the practical paranoid. No Starch Press.

One of the earliest books on OpenBSD. Endorsed by de Raadt, written by a longtime evangelist. [BSD books are often preceded by preambles about freedom that are Libertarian-inspired.]

- Article 19. 2020. How the Internet Really Works. No Starch Press.

Friendly introduction with lots of illustrations including often glossed over topics such as BGP - border gateway protocol.

\section{MANGA}

- Otomo. Akira.

Collected vol. 3 has some of the most stunning art in the entire series (large-scale, urban, destruction). Vol. 6 has the best body horror and some of the most tragic passages i.e. Tetsuo's increasingly out of control transformations, which lessen his humanity. Dark Horse's edition has useful "The story so far" introductions.
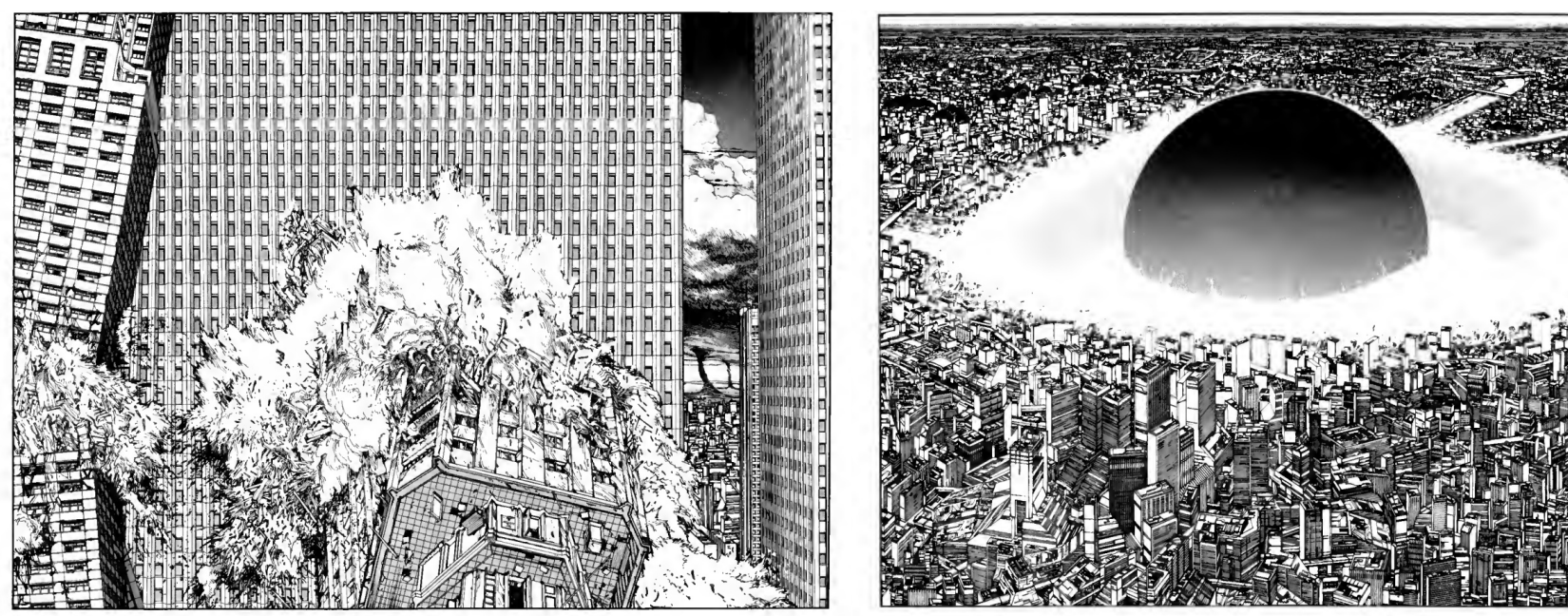


\section{PRIMARY SOURCES : HACKER MAGAZINES}

- GNU's Bulletin (1986-..)

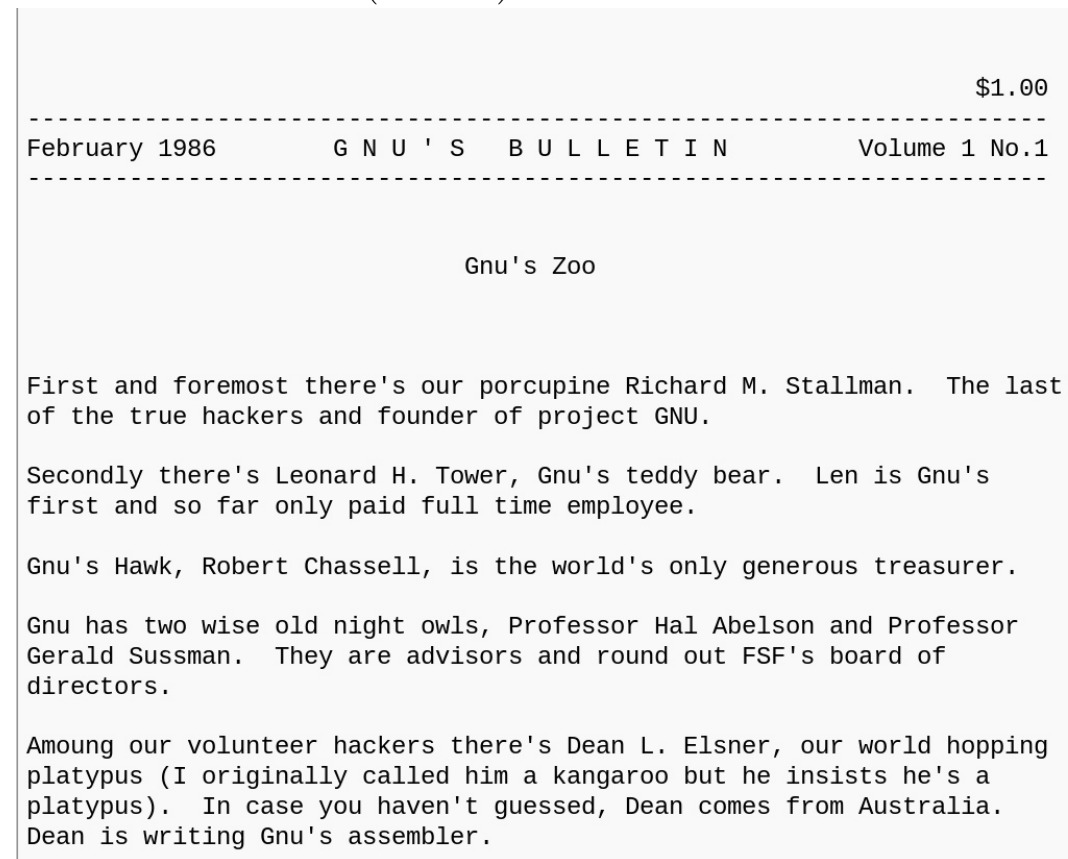

[The table of contents was cut from the image above and is rendered below :]

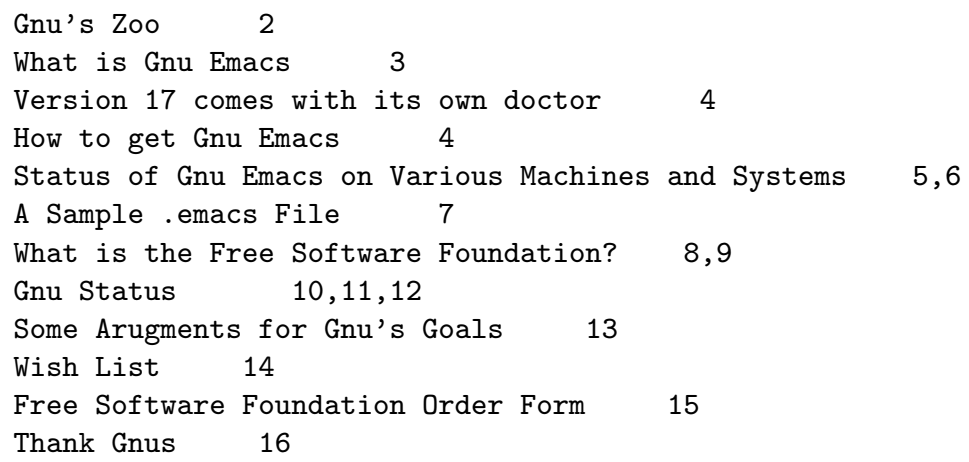

\section{PRIMARY SOURCES : PC MAGAZINES}

— Byte, "the small systems journal" (1975-..)

From the September 1975 first issue's first article : What is Byte? (by Carl Helmers) : "a monthly compendium of information for the owners and users of the new microcomputer systems becoming widely available at moderate cost." 


selected issues
\begin{tabular}{|l|l|}
\hline issue 1, sep. 75 & "Computers - the World's Greatest Toy!" \\
$2(8)$, aug. 77 & APL \\
$2(12)$, dec. 77 & Star Trek cover \\
$4(8)$, aug. 79 & LISP \\
$6(5)$, may 81 & Software Piracy \\
$7(9)$, sep. 82 & "Computers and the Disabled" \\
$16(4)$, april 91 & Soviet computing \\
\hline
\end{tabular}

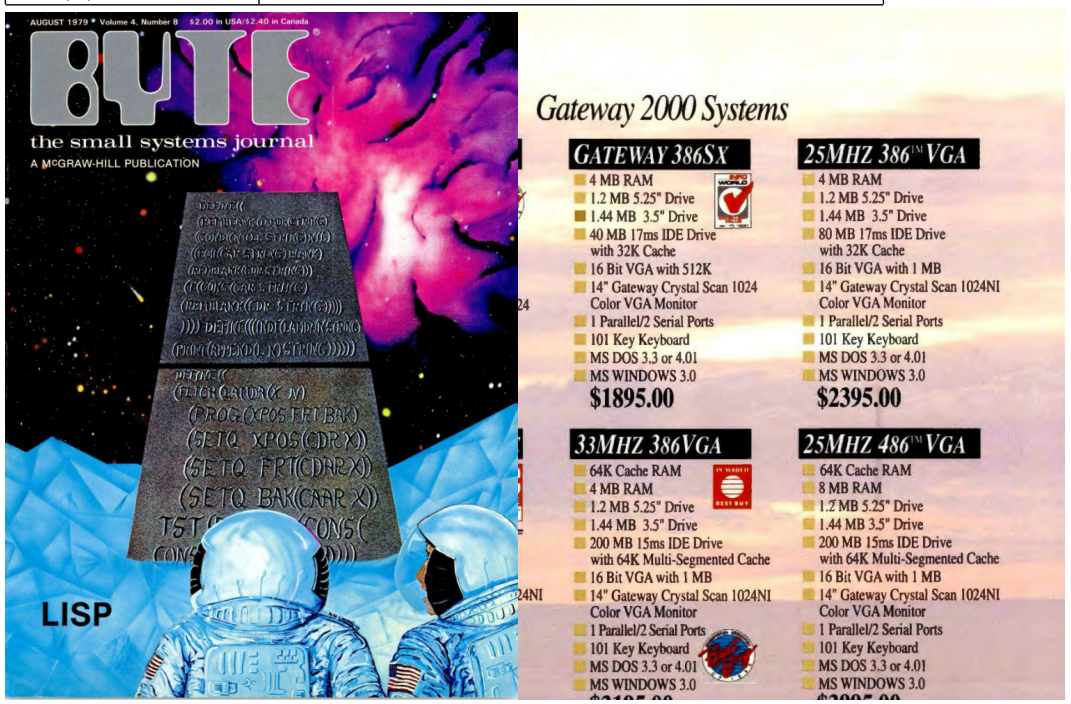

Il. : LISP issue, and personal computers advertised for two-thousand 1991 dollars...

\section{DOCUMENTARIES}

— Trench, Marianne. 1990. Cyberpunk. circa $1 \mathrm{~h}$

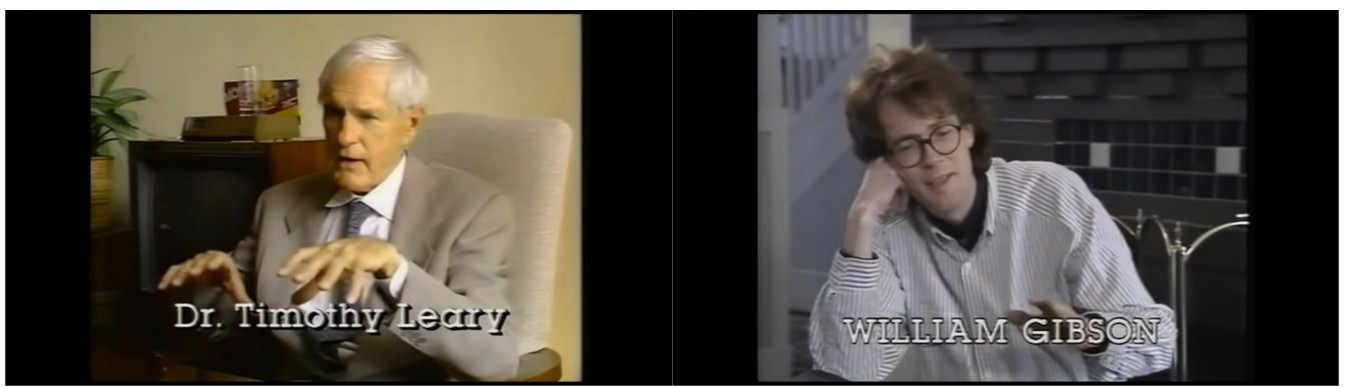

Leary defines cyberpunk as a person, not a genre, so :

"Cyberpunk is this person who takes navigational control over the cybernetic, electronic equipment and uses it - not for the army and not for the government, not for the Lufthansa airline, but of for his or her own personal purpose." 